\title{
EFFECT OF GROUND PROXIMITY ON AERODYNAMIC FORCES AND MOMENTS OF REUSABLE LAUNCH VEHICLE AT SUBSONIC SPEED
}

\author{
Gorfad Vijaykumar Devraj ${ }^{1}$, Manish Kumar ${ }^{2}$, Rajan Lakra ${ }^{3}$, Priyank Kumar ${ }^{4}$ \\ ${ }^{1}$ Department of Space Engineering and Rocketry, Birla Institute of Technology, Mesra, Ranchi \\ ${ }^{2}$ Department of Space Engineering and Rocketry, Birla Institute of Technology, Mesra, Ranchi \\ ${ }^{3}$ Department of Space Engineering and Rocketry, Birla Institute of Technology, Mesra, Ranchi \\ ${ }^{4}$ Department of Space Engineering and Rocketry, Birla Institute of Technology, Mesra, Ranchi
}

\begin{abstract}
This paper explores the effect of ground proximity on aerodynamics forces and moments acting on reusable launch vehicle at the time of its landing. As the name indicates the concept of reusability is attractive especially in case of Space Transportation and launch vehicles as it reduces the mission cost. The design of Reusable Launch vehicle is also very critical as the vehicle has to pass through various speed ranges from hypersonic to subsonic. RLV wing is generally low aspect ratio double delta wing which is very sensitive to ground effect due to the characteristic excessive vehicle attitudes associated with the landing and touchdown phases of flight.. In present study, a RLV model of $260 \mathrm{~mm}$ total length and reference area of $155 \mathrm{~mm} 2$ had been modeled using CAD tools. It has double delta wing of wing span 144mm and mean chord of $76 \mathrm{~mm}$ and vertical stabilizer of height $38 \mathrm{~mm}$. Effect of ground proximity on aerodynamic forces acting on RLV has been studied using commercial CFD software. During present analysis computational analysis has been done for different height. Height of RLV is varied from free flight condition to landing touchdown height and the angle of attack has been varied for $0 \square$ to $20 \square$. The complete study is done for lower subsonic speed at Reynolds number of $1.8 * 106$ for fix ground and moving ground conditions separately.
\end{abstract}

Keywords: Reusable Launch Vehicle, Ground Effect.

\section{INTRODUCTION}

Towards the goal to lift large payload into the space countries like America, France, Japan, Germany, India, china, Russia, etc have taken steps to build launch vehicles that carry men and material into space. With the increase in space exploration for space laboratories, space power stations, space defense etc., the concept of space launch has translated into space transportation. The cost of access to space is the deciding factor for all new avenues. To economically explore the space environment, it is necessary to reduce the cost by an order of magnitude.

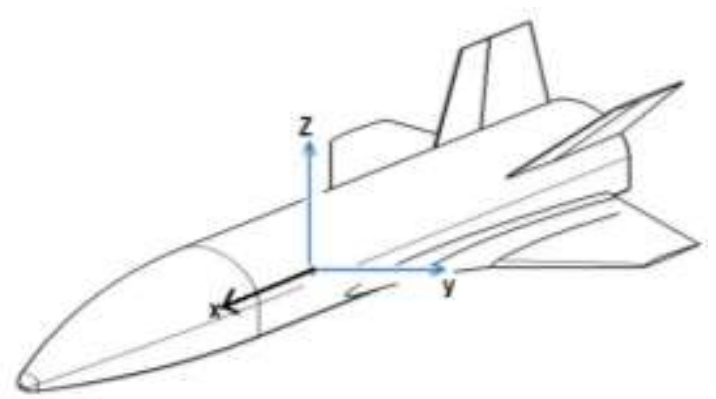

Fig-1 RLV Model

Reusable Launch vehicle is the concept that seems attractive because of its economical aspect and cost effectiveness. Researchers are working more on this concept to make space exploration more cost effective. There are mainly two approaches to develop reusable launch vehicle viz single stage and two stage orbit vehicles. In two stage orbit vehicle approach, the first stage is optimizes first stage for atmospheric operation and 2nd stage is optimized for upper atmosphere and reentry operation. RLV (Reusable launch vehicle) because of its high cross-range requirement during re- entry is configured as a low aspect ratio wing vehicle, and as a design concept, requires complete evaluation of its total flight envelope. [1] With respect to the landing phase of this flight envelope, The RLV, representative of the low aspect ratio wing class of aircraft, was tested for evaluation of its longitudinal flight characteristics in the presence of ground effects.
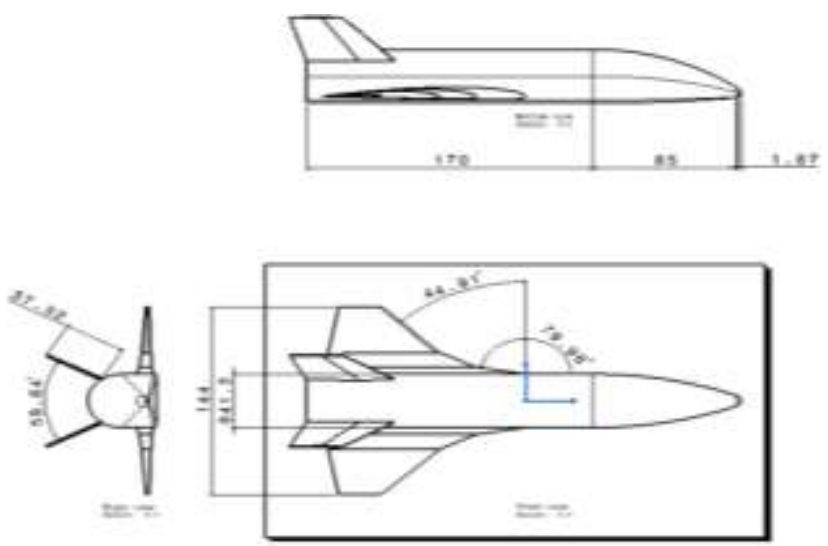

Fig 2- Detailed RLV Sketch 
As the reusable launch vehicle has to be landed on ground safely with or without humans inside, the landing phase has to be smooth enough. As the RLV approaches the ground there will be effect of ground proximity on the vehicle which can de stabilize it and also affects aerodynamics forces acting it. Ram effect increases the life coefficient due to which the RLV can float and bounce on the runway which can affect landing operation of the Reusable launch Vehicle.

\section{RESEARCH METHDOLOGY}

The complete study is focused on investigating effect of ground proximity on aerodynamic forces and moments of the Reusable Launch Vehicle by examining the Aerodynamic forces at different height from ground at various angles of attack.

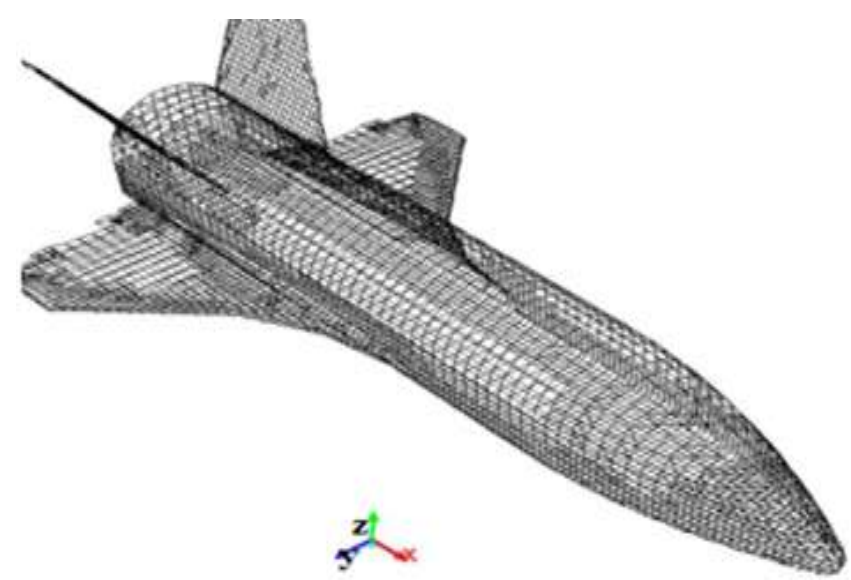

Fig- 3 surface grid on RLV Body

For this investigation height has been varied from $\mathrm{h} / \mathrm{b}=1.5$ to $h / b=0.05$ while angle of attack varied from $\alpha=0^{\circ}$ to $\alpha$ $=20^{\circ}$. Ground effect comes in to picture for the height equal to less than the wing span of the vehicle or chord of the aerofoil $^{[4]}$. In the case of RLV $h=1.5 b$ can be considered as free flight distance as ground will not have any effect of the flow field over RLV .Landing gear height has been taken as $0.05 b^{[2]}$. RLV model of the dimensions given in figure 2 has been created using design tool Catia V5, while preprocessing has been carried out in GAMBIT.

\subsection{Computations}

3-D simulation has been carried out in fluent adopting unsteady laminar, segregated, implicit $2^{\text {nd }}$ order scheme. For turbulent case simulation has been carried out in fluent adopting steady implicit k- $\varepsilon$ turbulent model with $2^{\text {nd }}$ order. This turbulent model has been chosen after carrying out various grid independence test and comparison with experimental results reported in reference ${ }^{[5]}$. The necessary boundary conditions has been given viz, Inlet, Outlet, Wall, and ground has been chosen as fix wall type of boundary. Figure 3 shows the surface grid as well as computational domain which has been used during entire computational analysis.

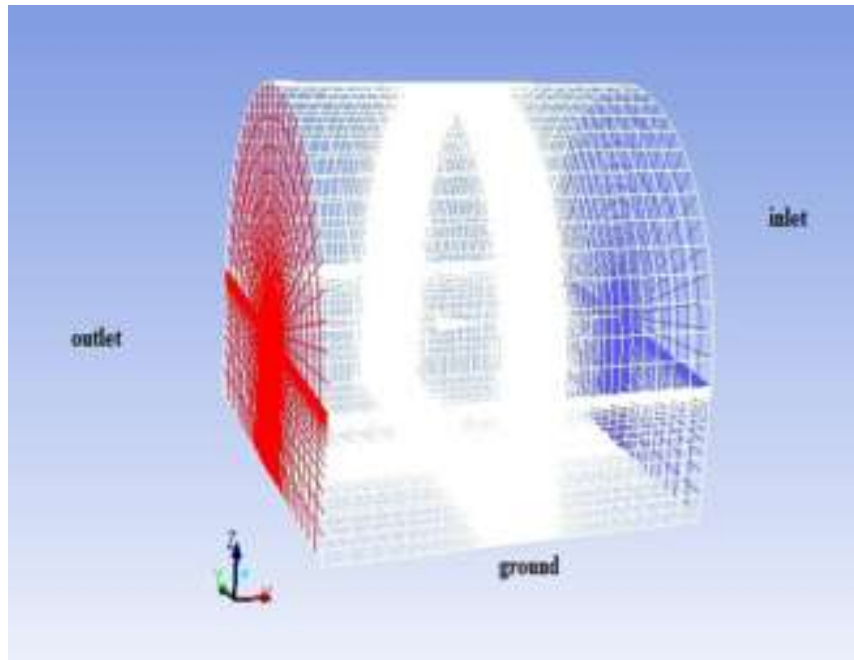

Fig 4 Structured grids over RLV using C-H Domain

\section{RESULT}

\subsection{Effect on Aerodynamic Forces}

Figure 4 shows the plot of $\mathrm{CL} \mathrm{v/s} \mathrm{h/b} \mathrm{at} \mathrm{different} \mathrm{angles} \mathrm{of}$ attack $(\alpha)$. And figure 4.12 shows the variation of CL v/s $\alpha$ at different ground clearance $(h / b)$. it is found that the effect of the ground seems to be negligible beyond $h / b=0.45$ and the ground effects are almost identical to the free body cases. At $\mathrm{h} / \mathrm{b} \leq 0.2$, the ground effects are more dominant at high angles of attack. However at lower angles of attack, it seems the ground effect does not affecting the flow at all. It is observed that the coefficient of lift increases as the height of RLV decrease with respect to ground. I.e. CL increase as $\mathrm{h} / \mathrm{b}$ decreases. This increment in lift coefficient is because of the RAM effect. RAM effect is more effective in case of tapered sections. This is the reason that ground effect is more pronounced for vehicle approaching ground at high angle of attack. Maximum 38.25\% increment in lift is observed at $\mathrm{h} / \mathrm{b}=0.05$. Figure 5 shows the plot $\mathrm{CD} \mathrm{v} / \mathrm{s} \mathrm{h} / \mathrm{b}$ at different angles of attack $(\alpha)$. And figure 4.14 shows the variation of $\mathrm{CD} v / \mathrm{s} \alpha$ at different ground clearance. No major difference was noted from the drag coefficient plots for all $\mathrm{h} / \mathrm{b}$ ratios investigated, especially at lower angles of attack. The drag coefficient increases with decrease in ground clearance $(\mathrm{h} / \mathrm{b})$ for higher angles of attack. The increment in drag at high angles of attack is due to increment in induced drag which could not decreased or overcome by low aspect ratio wing of RLV. Figure 6 the variation of $\mathrm{L} / \mathrm{D} v / \mathrm{s} \alpha$ at different ground clearance for different ground clearance $(\mathrm{h} / \mathrm{b})$. Lift-to-drag plots reveal a great increase with ground proximity where ratios of as high as 5.85 are noted at $\mathrm{h} / \mathrm{b}=0.05$. These values are almost 1.25 times that of the ground-free case $(\mathrm{L} / \mathrm{D}=4.7)$. It was observed that at $h / b=0.4$ the wing seems to be out of the influence of the ground at the lower angles of attack; however, ground influence is still apparent at higher angles of attack. 


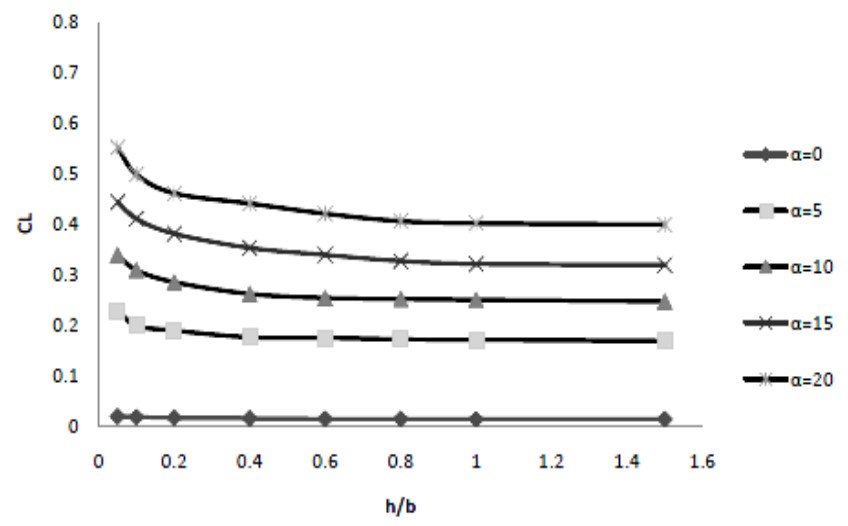

Fig 5 Effect of ground clearance (h/b) on CL

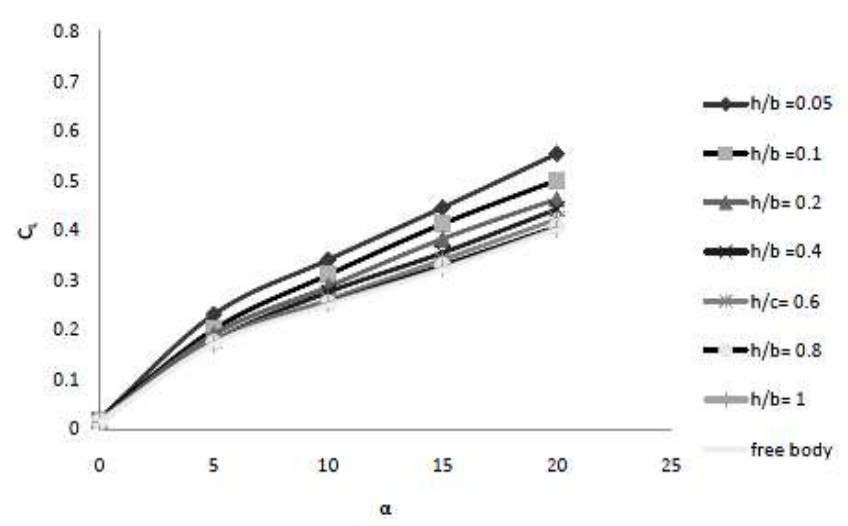

Fig 6 Effect of ground clearance $(\mathrm{h} / \mathrm{b})$ on $\mathrm{CL} v / \mathrm{s} \alpha$

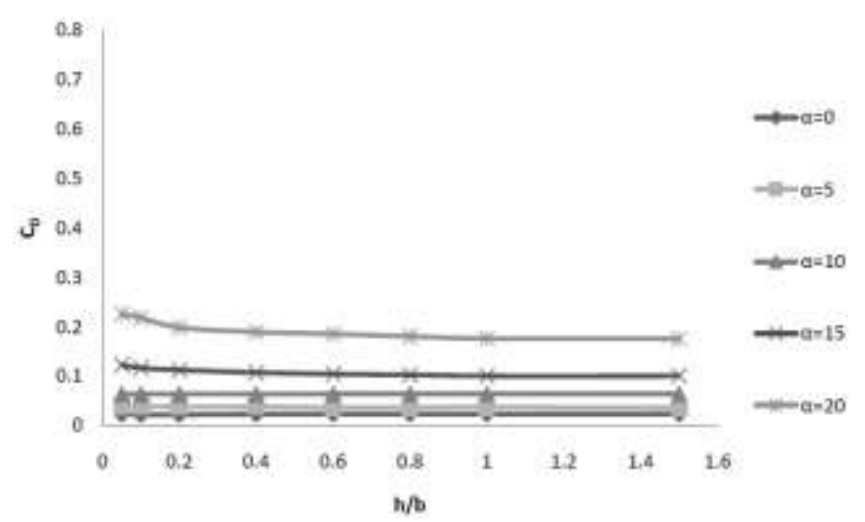

Fig 7 Effect of ground clearance $(\mathrm{h} / \mathrm{b})$ on $\mathrm{CD}$

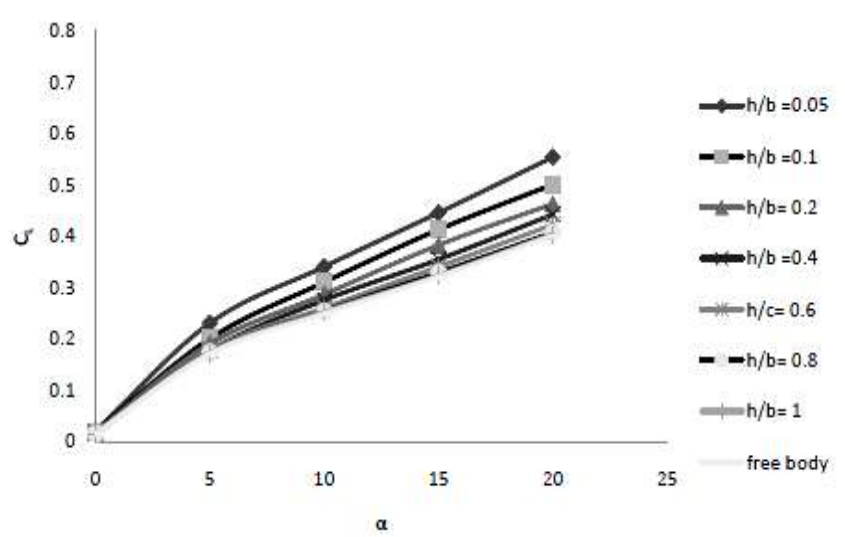

Fig 8 Effect of ground clearance $(\mathrm{h} / \mathrm{b})$ on $\mathrm{CD} v / \mathrm{s} \alpha$

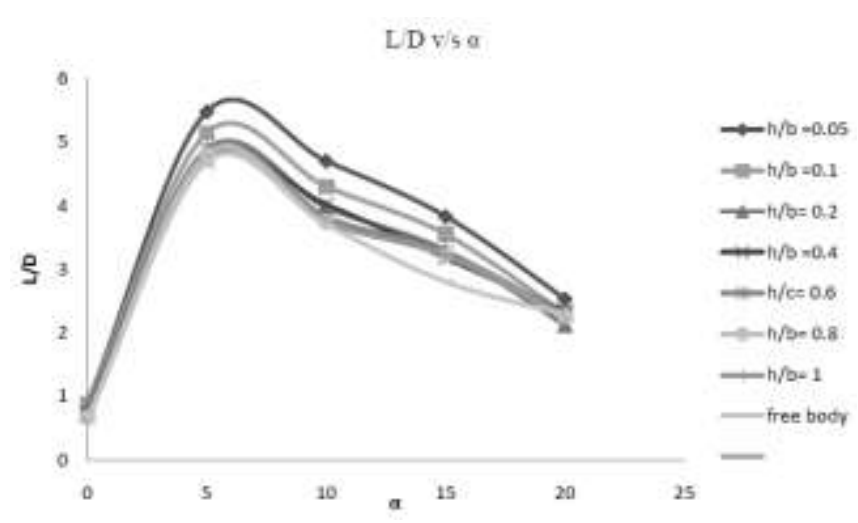

Fig 9 Effect of ground clearance $(\mathrm{h} / \mathrm{b})$ on $\mathrm{L} / \mathrm{D}$ v/s $\alpha$

\subsection{Effect on Moment Coefficients}

The nose-down moment coefficient increases near the ground as shown in Figure $7 \& 8$. The coefficient $\partial \mathrm{Cm} / \partial \alpha$ is nearly constant with changing non-dimensional height, portrayed by the nearly constant difference between curves in the figure. At lower non-dimensional heights $\partial \mathrm{Cm} / \partial \alpha$ is slightly greater, indicating that as the RLV begins to flare and increase its angle of attack, the nose-down pitching moment increases slightly. Figure 9 shows the graph for CMR v/s $\alpha$ for different ground clearance, here $\alpha$ varies from 0 to 20 degree. CMR remains nearly zero at all angles of attack and ground clearance. Figure 10 shows the graph for CMY v/s $\alpha$ for different ground clearance $(h / b)$, here $\alpha$ varies from 0 to 20 degree. The yawing moment coefficient (CMY) is calculated with respect to centre of gravity of the $\mathrm{RLV}$ model which is at a distance of $\mathrm{X} / \mathrm{L}=0.59$ from the nose tip.

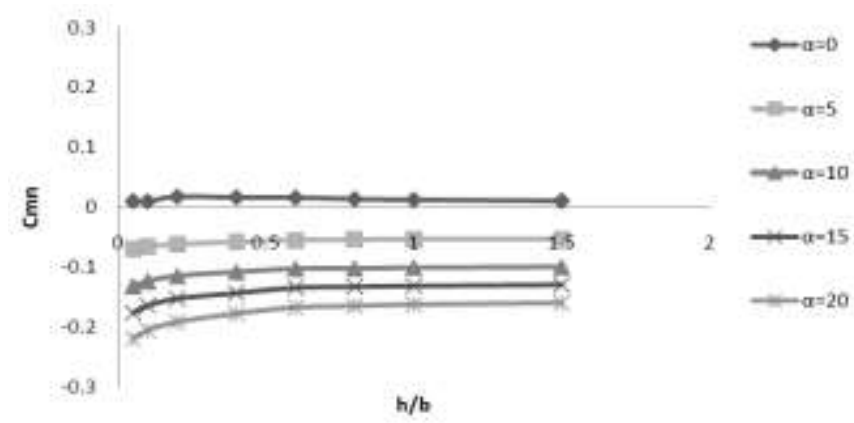

Fig 10 Effect of ground clearance $(\mathrm{h} / \mathrm{b})$ on $\mathrm{CMn}$ with different angles of attack

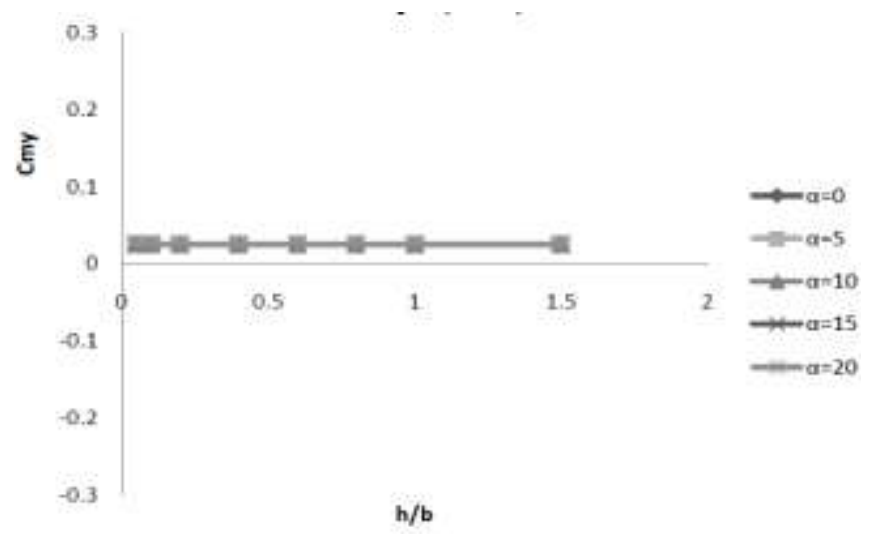


Fig 12 Effect of ground clearance (h/b) on Cmy with different angles of attack

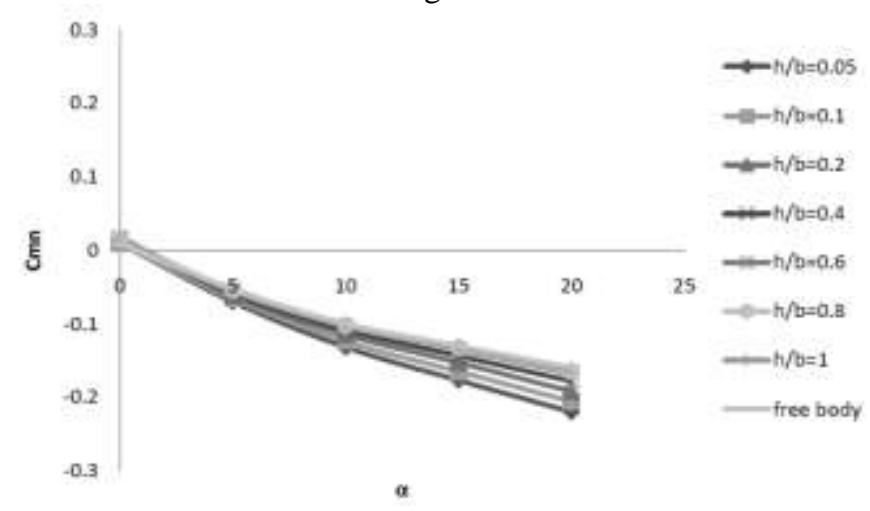

Fig 11 Effect of ground clearance (h/b) on CMn with different angle of attack

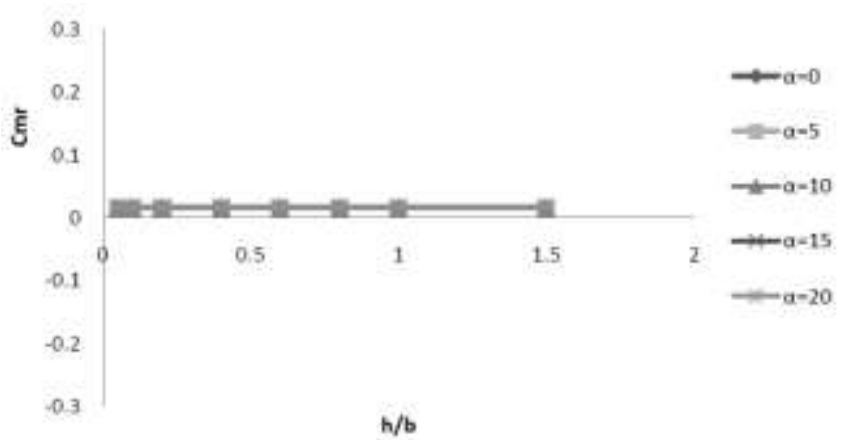

Fig 13 Effect of ground clearance $(\mathrm{h} / \mathrm{b})$ on $\mathrm{Cmr}$ with different angles of attack

\section{CONCLUSION}

In present investigation an effort has been made to study the complex flow field on RLV model when it operates near ground proximity. The main motivation behind this investigation was to study the effect of ground clearance on aerodynamic forces and moments of the RLV model. The important conclusions of the present study $\mathrm{c}$ are summarized as follows.

1. RLV remains under the influence of ground for ground clearance $(\mathrm{h} / \mathrm{b}) \leq 0.4$. The ground clearance more than $\mathrm{h} / \mathrm{b}=0.4$ the effect is small enough. Effect of ground clearance becomes prominent at $h / b \geq 0.2$. At zero and low angle of attack and The effect of ground clearance is negligible or too small but it increases with increase in angle of attack of RLV

2. As RLV approaches the ground, lift coefficient (CL) increases. The maximum increment in $\mathrm{CL}$ is around $38 \%$ at $\mathrm{h} / \mathrm{b}=0.05$. The rate of increase of $\mathrm{CL}$ remains approximately constant for all angles of attack.

3. Coefficient of drag (CD) does not get affect at low angle of attack but it also increases at higher angle of attack. It may be because wing with low aspect ratio experience more induced drag than the wing with high aspect ratio. The effect of ground clearance is not enough to reduce the total drag.
4. The pitching moment coefficient increase under the ground influence. Whereas the rolling moment and yawing moment coefficient remains unaffected.
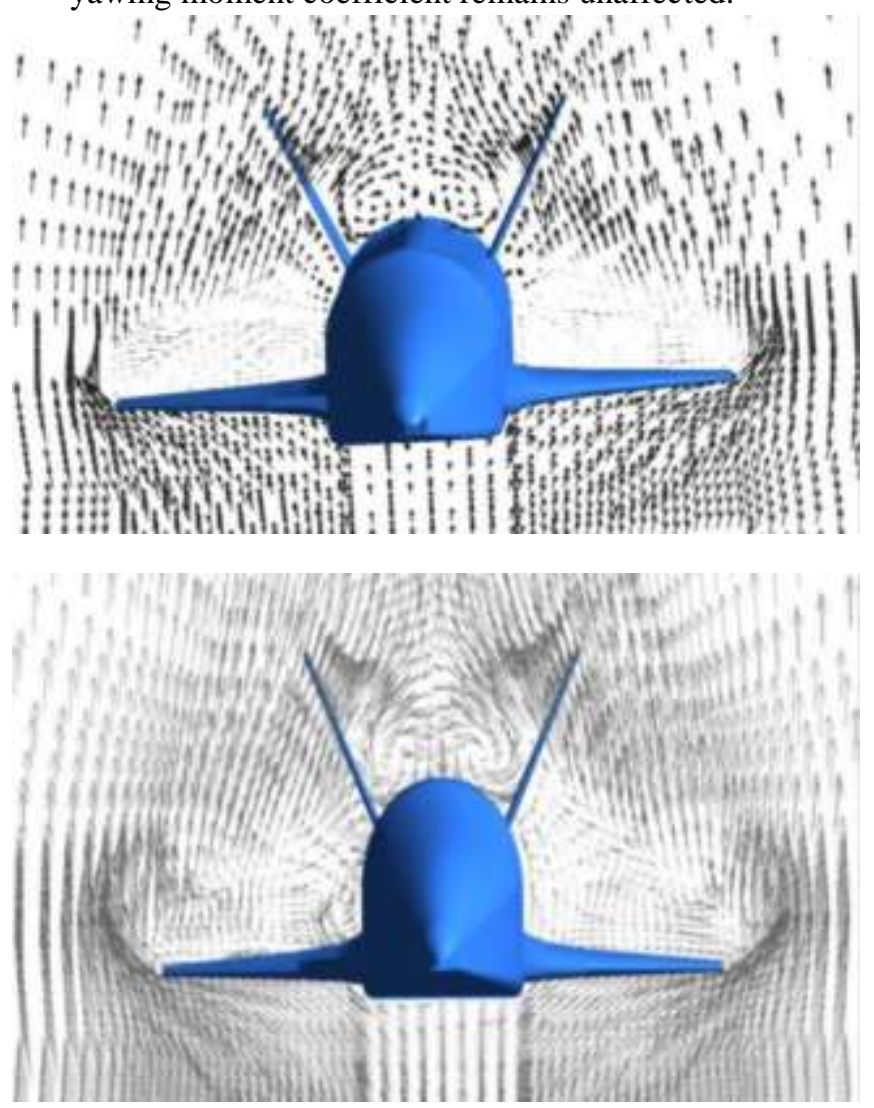

Fig 14 (a) \& (b) Velocity vector for $\alpha=20 \mathrm{deg}$ (free body) \& $(\mathrm{h} / \mathrm{b}=0.05)$, at $\mathrm{x} / \mathrm{c}=0.8$

Nomenclature-

CD - Drag force coefficient

CL - Lift force coefficient

CMn - Pitching moment coefficient

CMy - Yawing moment coefficient

CMr- Rolling moment coefficient

$\mathrm{h} / \mathrm{b}$ - Ground clearance (height from ground to wing span ratio)

RLV- Reusable launch vehicle

\section{ACKNOWLEDGEMENT}

The authors would like to acknowledge the technical help and guidance of Prof. Dr. J. K. Prasad, Mr. Sidhyant Kumar, Mr. PawanOjha, Mr. MrigankShahai, Mr. Pawan Kumar Karn, Mr. YogeshBhawarkar, Mr. L S Rao, Mr. RajanLakra, Mr. SaugataMondal,Mr. Satish Kumar, Mr. Jitram, and Mr. Hareram, who have supported and helped us in our work..

\section{REFERENCES}

[1]. Subhash, A.N., "Aerodynamics design aspects of a winged RLV”- SAROD DEC 08-09

[2]. Y.PARTE, et,al. " aerodynamic configuration design of RLV", 17th national convention of aerospace engineers and national seminar on Indian aerospace vehicles: technological challenges, B.I.T,2003 
[3]. Wing-in-ground effect vehicles Kirill V.

Rozhdestvensky_Saint-Petersburg ,2006

[4]. Young J. Moon Hyeon-Joon Oh, Jung-HeeSeo , "Aerodynamic investigation of three-dimensional wings in ground effect for aero-levitation electric vehicle", Department of Mechanical Engineering, Korea University, Seoul 136-701, Korea ,16 February 2005

[5]. Rakesh R, "investigation of flow field over a typical RLV model at subsonic speed", M.E. Thesis, B.I.T.MESRA, MAY-2011

[6]. M. Musaj, S. A. Prince conducted a numerical and experimental investigation of the aerodynamics of an unconventional w-leading

[7]. Edge reversed delta wing in ground effect, 26th international congress of the aeronautical sciences

\section{BIOGRAPHIES}

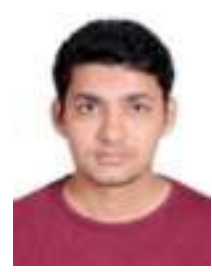

Gorfad Vijaykumar Devraj is currently working as an Assistant Professor in Annasaheb Dange College of Engineering Sangli. He completed Master of Engineering (M.E) in Space Engineering \& Rocketry from Birla Institute of Technology Mesra and B.E. in Aeronautical Engineering from IIAEIT, Pune.

E-id:gorfadvijay@gmail.com

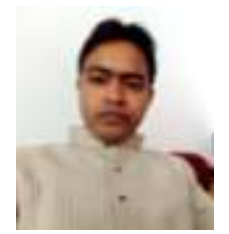

Mr. Manish Kumar is currently working as an Assistant Professor in Priyadarshini College of Engineering Nagpur. $\mathrm{He}$ completed Master of Engineering (M.E) in Space Engineering \& Rocketry from Birla Institute of Technology Mesra and B.E. in Aeronautical Engineering from Hindustan University, Chennai. E-id:manisrob@gmail.com

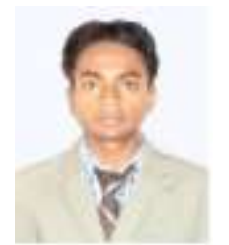

Mr. Rajan Lakra M.E in Space Engineering \& Rocketry from BIT, Mesra. Ranchi, India, after completing B.E in Aeronautical Engineering From Anna University, presently working as Assistant Prof at Priyadarshini College of Engineering Nagpur Email id: rajanlakra@gmail.com

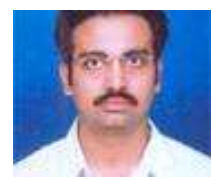

Currently working as a Assistant Professor in Birla Instittute of Technology Mesra. E-i.d: priyankkumar@bitmesra.ac.in 